\title{
Understanding the financial and psychological impact of employment disruption among caregivers of pediatric HSCT recipients: a mixed methods analysis
}

\author{
Caitlin B. Biddell ${ }^{1,2} \cdot$ Kimberly A. Kasow $^{2,3} \cdot$ Mary K. Killela $^{4} \cdot$ Kristin M. Page $^{5} \cdot$ Stephanie B. Wheeler $^{1,2}$. \\ Sarah W. Drier ${ }^{2} \cdot$ Matthew S. Kelly $^{6} \cdot$ Joanna M. Robles $^{7,8} \cdot$ Lisa P. Spees $^{1,2}$
}

Received: 2 November 2021 / Accepted: 28 January 2022 / Published online: 7 February 2022

(c) The Author(s), under exclusive licence to Springer-Verlag GmbH Germany, part of Springer Nature 2022

\begin{abstract}
Purpose Pediatric hematopoietic stem cell transplantation (HSCT) confers a substantial financial burden onto patients' families. In addition to high direct medical costs, HSCTs typically require at least one caregiver to take time away from work or other responsibilities, often leading to reduced household income. Using mixed methods, we sought to understand the impact of pediatric HSCT on caregiver employment and financial need.

Methods We surveyed caregivers of living pediatric patients who underwent HSCT at one of two southeastern transplant centers between 2012 and $2018(N=95)$. We then interviewed a subset of caregivers $(N=18)$ to understand whether and how employment disruption contributed to financial distress.

Results Among caregivers surveyed, the majority of household wage earners changed their work schedules to attend medical appointments and missed workdays. This resulted in income loss for $87 \%$ of families, with $31 \%$ experiencing an income reduction of over 50\%. Qualitative interviews pointed to four emergent themes: (1) employment disruption exacerbated existing financial challenges; (2) parental division of labor between caregiving and providing financially led to heightened psychological distress; (3) existing employment leave and protection resources were essential but not sufficient; and (4) the ability to work remotely and having a supportive employer facilitated employment maintenance throughout the HSCT process. Conclusion Expanded employment protections and access to accommodations are needed to limit the impact of HSCT on household income, health insurance, and financial hardship. Additionally, interventions are needed to ensure caregivers are equipped with the information necessary to navigate conversations with employers and prepare for the financial and psychological reality of employment disruption.
\end{abstract}

Keywords Financial toxicity $\cdot$ Employment disruption · Caregivers $\cdot$ Pediatric HSCT

Lisa P. Spees

lspees21@live.unc.edu

1 Department of Health Policy and Management, Gillings School of Global Public Health, University of North Carolina at Chapel Hill (UNC-CH), Chapel Hill, NC, USA

2 Lineberger Comprehensive Cancer Center, UNC-CH, Chapel Hill, NC, USA

3 Department of Pediatrics, UNC-CH, Chapel Hill, NC, USA

4 School of Nursing, UNC-CH, Chapel Hill, NC, USA
5 Department of Pediatrics, Division of Pediatric Transplant and Cellular Therapies, Duke University Medical Center, Durham, NC, USA

6 Department of Pediatrics, Division of Infectious Diseases, Duke University Medical Center, Durham, NC, USA

7 Department of Pediatrics, Division of Pediatric Hematology-Oncology, Duke University Medical Center, Durham, NC, USA

8 Duke Cancer Institute, Durham, NC, USA 


\section{Introduction}

Hematopoietic stem cell transplantation (HSCT) is increasingly performed in pediatric patients with a range of lifethreatening illnesses, including hematologic malignancies, genetic and metabolic disorders, and immunodeficiencies and nonmalignant diseases such as primary immunodeficiencies and hemoglobinopathies, among others [1]. Potentially curative, HSCT is a medically intensive process, with direct medical costs for pediatric allogeneic and autologous transplants averaging $\$ 585,300$ and $\$ 244,337$, respectively, at 100-day follow-up [2]. As healthcare costs are increasingly passed to insured patients [3], pediatric HSCTs can confer a substantial financial burden onto families [4]. Additionally, HSCTs require prolonged hospitalizations, ranging from a mean of 26 days for autologous to 54 days for allogeneic transplants [2], which often require caregivers to take time away from work $[4,5]$. Further, following patient discharge, caregivers must manage intensive outpatient follow-up care $[6,7]$. Though the extent of employment disruption may depend on employment type and accommodations [8-10], it is consistently associated with financial and psychological burden among caregivers of adults with cancer and other chronic illnesses [11-15].

Despite the unique and substantial demands faced by caregivers of pediatric HSCT recipients, little is known about the emotional and financial costs associated with employment disruption in this population. To date, a single study has described the experience of financial hardship, or financial toxicity, among families of pediatric HSCT recipients during the first year post-transplant [4]. While this study found that substantial income loss ( $>40 \%$ ) was a primary contributor to financial distress, it used percent of annual income lost as the sole indicator of employment disruption. To comprehensively describe the long-term and nuanced impact of employment disruption on financial toxicity in this population, we conducted a mixed methods analysis of caregivers of children who underwent allogeneic or autologous HSCT in the prior 2 to 8 years.

The objective of this study was to describe the financial needs of caregivers of pediatric HSCT recipients. Specifically, we used quantitative survey data and qualitative interview data to understand the impact of pediatric HSCT on caregiver employment and the relationship between employment disruption and financial need. Additionally, we sought to describe the resources used by caregivers to mitigate employment disruption and identify gaps in available resources.

\section{Materials and methods}

\section{Study population}

This study was conducted between May 2020 and January 2021. Eligible participants were caregivers of pediatric HSCT recipients $(<18$ years of age at the time of transplant) who underwent allogeneic or autologous HSCT between January 1, 2012, and December 31, 2018, at one of two Southeastern academic medical centers. Despite these transplant centers being located in adjacent cities, the programs differ in terms of transplant center size and the patient populations served, resulting in a cohort of participants from diverse backgrounds and experiences. We excluded caregivers of deceased patients or patients residing outside of the USA. Caregiver contact information and patient clinical information (e.g., HSCT date) were collected from patients' electronic health records. Of the 260 caregivers approached for the study, $38 \%$ completed the survey electronically $(N=49)$ or by phone $(N=50)$. Four participants were excluded due to not responding to the employment section of the survey for a final sample of $N=95$ and a response rate of $36.5 \%$. Clinical characteristics (i.e., sex, HSCT type, HSCT year, diagnosis, graft versus host disease) of patients did not differ between respondents and nonrespondents based on nonsignificant $(p>0.05)$ chi-squared test results. The institutional review boards at both institutions approved the study (UNC-CH IRB\#19-0490).

\section{Quantitative data collection and analysis}

Eligible caregivers were sent the electronic survey by email. After four email reminders, the remaining caregivers were contacted by phone. Data was recorded, deidentified, and managed using REDCap, an electronic data capture tool [16]. After caregivers consented to participation, the survey collected information on the family's sociodemographic characteristics, financial toxicity, and financial resources used (Online Resource 1). Financial toxicity was measured using an adapted patient-reported outcome measure, the COST Score, which has been validated in adult patients with cancer (range: $0-44 ;<22$ indicates high financial toxicity) [17]. We pilot tested the survey with two caregivers to ensure questions appropriately captured domains of interest. Respondents were given a \$20 Amazon gift card for their time.

The survey asked participants to describe the impact of their child's HSCT on the employment of all wage earners in the family. For caregivers reporting more than one wage earner, they were asked to categorize them as primary and 
secondary. Employment-related survey questions were adapted from questions in the published literature investigating employment disruption in adult patients with cancer [18-20].

\section{Qualitative data collection and analysis}

Upon survey completion, respondents indicated whether they would be willing to participate in a follow-up phone interview. During 30- to 60-minute semi-structured interviews, a member of our research team (SD) asked caregivers to describe the medical (e.g., insurance bills) and nonmedical (e.g., reduced income) financial impact of HSCT, discuss financial resources used, and provide recommendations for reducing financial challenges of pediatric HSCT caregivers moving forward. Caregivers with high financial toxicity (COST score $<22$ ) were prioritized for interviews. Participants were given another $\$ 50$ gift card for interview completion. We conducted interviews until reaching thematic saturation, and interviews were audio recorded and transcribed verbatim.

Interview transcripts were organized and analyzed using Dedoose (version 9.0.15) [21]. Using directed content analysis [22], a team of two coders (CBB, LPS) created a coding scheme with domains informed by a conceptual model of financial toxicity in pediatric oncology [23]. This model explores the financial impact of a childhood cancer diagnosis on material financial hardship, health-related coping behaviors, and psychological distress. Subcodes were deductively informed by literature on financial toxicity [24-27]. Inductive codes emerged during the iterative coding of the interviews. Resources and recommendations were coded by level of influence using the socio-ecological framework (i.e., policy, community, organization, interpersonal, individual) [28]. All coders (CBB, LPS, MKK) independently coded and compared two transcripts to confirm codes were applied systematically. After reaching consensus, additional transcripts were coded independently. Coded excerpts were analyzed to identify themes and subthemes. The Consolidated Criteria for Reporting Qualitative Research (COREQ) was used to guide the reporting of methods and results [29].

\section{Qualitative and quantitative integration}

We compared and contrasted the qualitative and quantitative findings in line with a convergent mixed methods study design [30]. The qualitative findings supplemented the quantitative survey results by adding a narrative understanding of employment disruption and identifying recommendations to minimize the impact of pediatric $\mathrm{HSCT}$ on caregiver employment.

\section{Results}

\section{Participant characteristics}

The average age of HSCT recipients was 7.6 years, and the median time from HSCT was 4 years (Online Resource 2). Of the 95 survey respondents, the majority of caregivers reported being mothers of the HSCT recipient (77\%) and married (79\%). When asked to report their 2019 household income, $21 \%$ reported making less than $\$ 50,000,33 \%$ between $\$ 50,000$ and $\$ 99,000$, and $43 \%$ over $\$ 100,000$ ( $3 \%$ did not disclose). The majority of caregivers reported that their child was privately insured at transplant (68\%), followed by Medicaid (33\%) and Tricare (9\%). COST scores ranged from 0 (high financial toxicity) to 41 (low financial toxicity), with a median of 17 and interquartile range (IQR) of 9-28 (Table 1).

The median COST score of the 18 interview participants was 12 (IQR 8-20). All caregivers interviewed were married but otherwise shared similar sociodemographic and clinical characteristics to the survey sample (Table 1, Online Resource 2).

\section{Patterns and trends in HSCT-related employment disruption}

Forty-eight survey respondents reported living in a single-earner household, and the remaining 47 respondents reported two or more wage earners. Over $80 \%$ reported that the sole or primary wage earner in their household was employed full time (Table 2). In the 12 months following HSCT, caregivers in single-earner households commonly reported that the sole wage earner changed their work schedule to attend medical appointments $(60 \%)$ and reduced work hours (40\%). In dual-earner households, caregivers reported that both primary and secondary wage earners changed their work schedules to attend medical appointments $(68 \%, 74 \%$, respectively) and reduced work hours overall (49\%, 54\%, respectively). Missed days of work during the year following HSCT were reported by the majority of employed wage earners; sole wage earners missed a median (IQR) of 25 (15-40) days, and in dualearner households, primary wage earners missed a median (IQR) of 23 (11-100) days, and secondary wage earners missed a median (IQR) of 23 (10-180) days (Table 2).

Several employment trajectories emerged from the qualitative interviews. The most common trajectory described was among families with both parents working and contributing to household income prior to the transplant. One parent, generally the secondary wage earner, left their job or severely reduced hours, some preemptively leading 
Table 1 Descriptive characteristics of survey and interview participants

\begin{tabular}{|c|c|c|}
\hline & $\begin{array}{l}\text { Survey participants } \\
(N=95)\end{array}$ & $\begin{array}{l}\text { Interview } \\
\text { participants } \\
(N=18)\end{array}$ \\
\hline COST score (median, interquartile range) & $17(9-28)$ & $12(8-20)$ \\
\hline \multicolumn{3}{|l|}{ Transplant center } \\
\hline UNC & $26(27 \%)$ & $7(39 \%)$ \\
\hline Duke & $69(73 \%)$ & $11(61 \%)$ \\
\hline \multicolumn{3}{|l|}{ Relationship to patient } \\
\hline Mother & $73(77 \%)$ & $15(83 \%)$ \\
\hline Father & $21(22 \%)$ & $3(17 \%)$ \\
\hline Other & $1(1 \%)$ & $0(0 \%)$ \\
\hline \multicolumn{3}{|l|}{ Marital status ${ }^{\mathrm{b}}$} \\
\hline Married & $75(79 \%)$ & $18(100 \%)$ \\
\hline Widowed & $1(1 \%)$ & $0(0 \%)$ \\
\hline Divorced & $8(9 \%)$ & $0(0 \%)$ \\
\hline Separated & $7(7 \%)$ & $0(0 \%)$ \\
\hline Single, never married & $4(4 \%)$ & $0(0 \%)$ \\
\hline \multicolumn{3}{|l|}{ Household size ${ }^{b}$} \\
\hline 3 or less & $30(32 \%)$ & $4(22 \%)$ \\
\hline 4 or 5 & $56(59 \%)$ & $12(67 \%)$ \\
\hline 6 or more & $9(9 \%)$ & $2(11 \%)$ \\
\hline \multicolumn{3}{|l|}{ Number of wage earners in the household ${ }^{b}$} \\
\hline 1 & $48(51 \%)$ & $8(44 \%)$ \\
\hline 2 or more & $47(49 \%)$ & $10(56 \%)$ \\
\hline \multicolumn{3}{|l|}{ Annual household income $e^{c}$} \\
\hline Less than $\$ 50,000$ & $20(21 \%)$ & $2(11 \%)$ \\
\hline$\$ 50,000$ to $\$ 99,999$ & $31(33 \%)$ & $6(33 \%)$ \\
\hline$\$ 100,000$ to $\$ 149,999$ & $20(21 \%)$ & $6(33 \%)$ \\
\hline$\$ 150,000$ or more & $21(22 \%)$ & $3(17 \%)$ \\
\hline Missing & $3(3 \%)$ & $1(6 \%)$ \\
\hline \multicolumn{3}{|l|}{ Health insurance coverage at transplant ${ }^{\mathrm{d}}$} \\
\hline Private (employer sponsored or marketplace) & $65(68 \%)$ & $12(67 \%)$ \\
\hline Medicaid & $31(33 \%)$ & $5(28 \%)$ \\
\hline Tricare & $9(9 \%)$ & $2(11 \%)$ \\
\hline
\end{tabular}

COST, COmprehensive Score for financial Toxicity; HSCT, hematopoietic stem cell transplantation

aAmong survey participants who were willing to be interviewed, we prioritized those with the lowest COST scores (i.e., participants who experienced high financial toxicity)

${ }^{\mathrm{b}}$ Participants reported their marital status, household size, and employment status during February 2020, prior to the start of the COVID-19 pandemic

${ }^{c}$ Participants reported their annual income from 2019, prior to the year that the survey was conducted

${ }^{\mathrm{d}}$ Participants could select multiple types of insurance, so sum does not add up to total participants up to the transplant, and others after exhausting leave resources; the primary wage earner continued working and would take sporadic leave for appointments.

"Well, I had to stop working, because me and my husband had decided that I would stay up at the hospital with [patient] during his treatments. I lost all of my income as a result, 'cause I resigned because I just was not able to work and take care of [patient] at the same time." (Participant \#65)
In contrast, among families with only one wage earner prior to transplant, the non-wage-earning parent typically took on primary caregiving responsibilities for the HSCT recipient, and the other parent continued in their employment, taking time off as needed.

Employment disruption commonly extended beyond the immediate transplant period. Several interviewees explained that the ongoing caregiving responsibilities precluded them from returning to work for several years following the transplant. Across the different employment trajectories 
Table 2 Employment status and impact of HSCT on employment in primary and secondary wage earners $(N=95)$

\begin{tabular}{|c|c|c|c|}
\hline & \multirow{2}{*}{$\begin{array}{l}\text { Single-earner households } \\
(N=48) \\
\text { Sole wage earner }\end{array}$} & \multicolumn{2}{|c|}{$\begin{array}{l}\text { Dual-earner households } \\
(N=47)\end{array}$} \\
\hline & & Primary wage earner & Secondary wage earner \\
\hline \multicolumn{4}{|l|}{ Relationship to patient } \\
\hline Mother/stepmother & $6(13 \%)$ & $16(34 \%)$ & $28(60 \%)$ \\
\hline Father/stepfather & $42(87 \%)$ & $28(60 \%)$ & $16(34 \%)$ \\
\hline Other $^{\mathrm{a}}$ & $0(0 \%)$ & $3(6 \%)$ & $3(6 \%)$ \\
\hline \multicolumn{4}{|l|}{ Employment status at transplant } \\
\hline Employed full time & $40(83 \%)$ & $38(81 \%)$ & $31(66 \%)$ \\
\hline Employed part time & $2(4 \%)$ & $3(6 \%)$ & $8(17 \%)$ \\
\hline Not employed ${ }^{b}$ & $6(13 \%)$ & $6(13 \%)$ & $8(17 \%)$ \\
\hline Sample of full-time and part-time employed earners only & $N=42$ & $N=41$ & $N=39$ \\
\hline \multicolumn{4}{|l|}{ Changes in a wage earner's employment 12 months post-HSCT } \\
\hline Temporarily changed work schedule to attend child's appts & $25(60 \%)$ & $28(68 \%)$ & $29(74 \%)$ \\
\hline Reduced work hours & $17(40 \%)$ & $20(49 \%)$ & $21(54 \%)$ \\
\hline Left job & $3(7 \%)$ & $4(10 \%)$ & $6(15 \%)$ \\
\hline Increased work hours & $4(10 \%)$ & $1(2 \%)$ & $0(0 \%)$ \\
\hline Changed job or careers & $2(5 \%)$ & $2(5 \%)$ & $3(8 \%)$ \\
\hline Retired early & $1(2 \%)$ & $1(2 \%)$ & $1(3 \%)$ \\
\hline No change to employment & $10(24 \%)$ & $9(22 \%)$ & $3(8 \%)$ \\
\hline Other change to employment & $6(14 \%)$ & $3(7 \%)$ & $5(13 \%)$ \\
\hline \multicolumn{4}{|l|}{ Missed days of work in the 12 months post-HSCT } \\
\hline Yes & $35(83 \%)$ & $35(85 \%)$ & $37(95 \%)$ \\
\hline No & $7(17 \%)$ & $6(15 \%)$ & $2(5 \%)$ \\
\hline \# of work days missed, median (IQR) & $25(15,40)$ & $23(11,100)$ & $23(10,180)$ \\
\hline
\end{tabular}

${ }^{a}$ Other wage earners included sisters, grandfathers, and not reported

${ }^{\mathrm{b}}$ Includes individuals who were retired, disabled, looking for work, etc.

${ }^{\mathrm{c}}$ Respondents could select all that apply, percentages calculated out of number of employed wage earners

described, four major themes emerged (see Table 3 for representative quotations). These themes chronologically describe the financial and psychological consequences of employment disruption, followed by an assessment of policy- and employer-level resources to ameliorate this disruption.

\section{Major theme \#1: Employment disruption exacerbated existing financial challenges associated with HSCT costs}

Employment disruption following HSCT led to income loss for most families surveyed (87\%), with $31 \%$ of families experiencing an income reduction of over $50 \%$ and an additional $17 \%$ experiencing a $25-50 \%$ reduction. Interviewees described financial challenges being exacerbated by the simultaneous experience of income loss, large medical bills, and additional HSCT-related household expenses. As a result, interviewees described using savings and retirement funds to pay household bills after losing one parent's income (Table 3).

In addition to income loss, privately insured families worried about maintaining employer-based health insurance. Though most interviewees were able to keep their child on the employer-sponsored health insurance of the parent who continued working, the threat of insurance loss loomed.

"There was a number of time[s] I wanted to quit. I didn't feel like I could because he was sick, and we needed insurance." (Participant \#247)

Even among families able to maintain continuous coverage, several experienced increases in their share of premium costs under the Consolidated Omnibus Budget Reconciliation Act (COBRA) and Family Medical Leave Act (FMLA):

"We had to pay basically the full amount of the premiums after a certain point which became pretty pricey." (Participant \#23) 
Table 3 Major themes related to employment disruption among caregivers of pediatric HSCT recipients $(N=18)$

Theme Illustrative quotes

Employment disruption exacerbated existing financial challenges associated with HSCT costs

Parental division of labor between caregiving and providing financially led to heightened psychological distress

Existing employment leave and protection resources were necessary but not sufficient for caregivers of HSCT recipients

Having the ability to work remotely and a supportive employer facilitated employment maintenance throughout the HSCT period
"Well, I had to stop working, because me and my husband had decided that I would stay up at the hospital with [patient's name] during his treatments. I lost all of my income as a result,'cause I resigned because I just was not able to work and take care of [patient's name] at the same time, or be at the hospital with him. That dropped us down to one income. That's why we were using the IRAs and the savings, because we still had mortgage. We had three other kids still at home, so with food and everything else, monthly expenses." (Participant \#65) "[The time after using up all accrued PTO or sick leave is] where we probably experienced some of the financial strains was going through that because, as you well know, none of the other things in life, whether it's your mortgage or light bill or any of that stuff gets put on pause." (Participant \#23)

"I think everybody was just very stressed, especially my husband. He pretty much takes care of most of paying all the credit card bills and things like that, and I do the mortgage and utilities. I think it was stressful for him, especially when he reduced his schedule for work, and just realizing that his entire paycheck would pretty much be gone." (Participant \#144)

"Because what happened with us was that I stopped working, but my husband continued to work. The challenge for me was that I had to do everything by myself, me, and my child." (Participant \#35)

"I just think families need so much more than FMLA's probably the biggest protection we have. That's only 12 weeks of job protection..." (Participant \#144)

"I started my "leave" with vacation time and then rolled it into a leave of absence for a health care circumstance. I actually had to give up my employment of 10 years. I basically forfeited my job because there's so much involved post-transplant too that I can't even imagine how somebody, like a single parent, would do this at all." (Participant \#182)

"I did the same thing, so that I could be with my daughter and my wife whenever I needed to be, for whatever reason, whether to give her a break, be there for treatments, whatever it may have been. I applied for that as well. It was basically same thing. In the early goin', I just used, when I took off, they would just throw whatever-vacation, personal days that type of thing that I had rolled over or saved. Once that was exhausted, if I went up there to, when [patient's name] was going through one phase of her treatment, I was up there for say a week or whatever, I would just taking time off. Nothing got affected as far as when I came back, it was still the same. Just I wasn't gettin' paid for that." (Participant \#23)

"Well, it was because I-I was able to work remotely, but the time that I had to put in wasn't there. I was not let go from my job. I was able to maintain my job, and my husband, I think he was able to as well. That was because we were able to work remotely." (Participant \#33)

"Fortunately, I have a fabulous employer, and I was able to work from the hospital. I could just work remotely as needed." (Participant \#211)

"I was lucky enough that my boss was very willing to work with my schedule, but I know a lotta people are not that lucky." (Participant \#144)

"We already had private health insurance. Actually his boss while we were in treatment changed his plan to a better plan, so that it would be less expensive." (Participant \#255) 


\section{Major theme \#2: Parental division of labor between caregiving and providing financially led to heightened psychological distress}

The psychological impact of financial distress also emerged as an important, and related, dimension of employment disruption. Gendered social norms influenced caregiving responsibilities; specifically, male caregivers, who most commonly maintained employment and made up $87 \%$ of wage earners in single-earner households and $59 \%$ of primary wage earners in dual-earner households (Table 2), felt pressure to provide financially and experienced psychological distress when they felt they could not provide sufficiently. In contrast, female caregivers felt the pressure of being the primary caregiver for the HSCT recipient, which often involved substantial emotional labor as well (Table 3). Several families discussed that this division of labor led to distress, bred resentment, and harmed their partnerships:

"I felt like I was working to pay the medical bills that the insurance was not paying...that affected our marriage because we were not able to spend time as a couple...it really did both financially and emotionally touch on every aspect of our lives." (Participant \#33)

Table 4 Facilitators of maintaining employment during HSCT among full-time and part-time employed wage earners

\begin{tabular}{|c|c|c|c|}
\hline & \multirow{2}{*}{$\begin{array}{l}\text { Single-earner households } \\
\text { Sole wage earners } \\
(N=42)^{\mathrm{a}}\end{array}$} & \multicolumn{2}{|l|}{ Dual-earner households } \\
\hline & & $\begin{array}{l}\text { Primary wage earners } \\
(N=41)^{\mathrm{a}}\end{array}$ & $\begin{array}{l}\text { Secondary wage earners } \\
(N=39)^{\mathrm{a}}\end{array}$ \\
\hline \multicolumn{4}{|l|}{ Discussed work impact with the patient's clinician } \\
\hline No & $20(48 \%)$ & $26(64 \%)$ & $24(62 \%)$ \\
\hline Yes & $14(33 \%)$ & $12(29 \%)$ & $8(20 \%)$ \\
\hline Not sure or missing & $8(19 \%)$ & $3(7 \%)$ & $7(18 \%)$ \\
\hline \multicolumn{4}{|l|}{ Discussed work impact with employer/human resources } \\
\hline No & $10(24 \%)$ & $12(29 \%)$ & $12(31 \%)$ \\
\hline Yes & $29(69 \%)$ & $26(64 \%)$ & $25(64 \%)$ \\
\hline Not sure or missing & $3(7 \%)$ & $3(7 \%)$ & $2(5 \%)$ \\
\hline \multicolumn{4}{|l|}{ Employer support provided during the first year post-HSCT } \\
\hline Flexible work schedule & $25(60 \%)$ & $23(56 \%)$ & $20(51 \%)$ \\
\hline Conversation about different leave options & $22(52 \%)$ & $19(46 \%)$ & $11(28 \%)$ \\
\hline Access to additional paid time off & $18(43 \%)$ & $13(32 \%)$ & $11(28 \%)$ \\
\hline $\begin{array}{l}\text { Access to assistance in understanding insurance benefits } \\
\text { and coverage }\end{array}$ & $15(36 \%)$ & $10(24 \%)$ & $6(15 \%)$ \\
\hline Change in job duties/responsibilities & $11(26 \%)$ & $12(29 \%)$ & $12(31 \%)$ \\
\hline Teleworking options & $9(21 \%)$ & $14(34 \%)$ & $11(28 \%)$ \\
\hline $\begin{array}{l}\text { Access to assistance with the child's medical and } \\
\text { nonmedical bills }\end{array}$ & $8(19 \%)$ & $7(17 \%)$ & $6(15 \%)$ \\
\hline Other $^{\mathrm{b}}$ & $12(29 \%)$ & $9(22 \%)$ & $8(21 \%)$ \\
\hline Sample of wage earners who missed workdays & $N=35$ & $N=35$ & $N=37$ \\
\hline \multicolumn{4}{|l|}{ Resources used during the first year post-HSCT } \\
\hline Paid vacation leave & $21(60 \%)$ & $27(77 \%)$ & $20(54 \%)$ \\
\hline Paid sick leave & $18(51 \%)$ & $27(77 \%)$ & $21(57 \%)$ \\
\hline Family Medical Leave Act (FMLA) & $15(43 \%)$ & $19(54 \%)$ & $14(38 \%)$ \\
\hline Unpaid leave & $13(37 \%)$ & $12(34 \%)$ & $10(27 \%)$ \\
\hline No resources for absences from work & $6(17 \%)$ & $3(9 \%)$ & $7(19 \%)$ \\
\hline Other & $9(26 \%)$ & $4(11 \%)$ & $2(5 \%)$ \\
\hline None & $6(14 \%)$ & $8(20 \%)$ & $6(15 \%)$ \\
\hline
\end{tabular}

${ }^{a}$ Employed wage earners only

${ }^{b}$ Other includes written in responses: sole wage earners (emotional support and understanding, care packages and dinners, donated leave, financial donations and fundraisers, paying for insurance while on leave, and hosting a bone marrow drive); primary wage earners (emotional support and understanding, care packages and dinners, financial donations, donated leave); secondary wage earners (emotional support and understanding, donated leave, covering mortgage cost) 


\section{Major theme \#3: Existing employment leave and protection resources were essential but not sufficient}

Among employed wage earners (sole, dual primary, and dual secondary) who reported missing work during the year following HSCT, resources used included paid vacation $(60 \%$, $77 \%, 54 \%$, respectively), paid sick leave $(51 \%, 77 \%, 57 \%)$, FMLA $(43 \%, 54 \%, 38 \%)$, and unpaid leave $(37 \%, 34 \%$, $27 \%$ ). Between 14 and $20 \%$ of wage earners reported not having any resources available for work absences (Table 4).

While job protection policies, such as FMLA and paid leave, including donated sick leave, were emphasized in both surveys and interviews, the interviews illustrated that the primary challenge with FMLA and paid leave is that they were finite. Given the intensive nature of HSCT, even 12 weeks of job protection (through FMLA) was not sufficient to cover staying in the hospital with the HSCT recipient for up to 3 months, often followed by several years of intensive outpatient follow-up care (Table 3 ).

Similarly, the amount of paid vacation and sick leave available was widely variable across employers. Though interviewed caregivers almost universally described using paid leave when available, only those who had access to coworkers willing to donate their leave or held senior positions with highly flexible paid leave could take substantial time off for caregiving responsibilities. However, paid leave was highlighted as an important resource for the secondary caregiver to attend important appointments or provide intermittent relief to the primary caregiver.

Though the majority of interviewees were employed in traditional work settings qualifying under FMLA and offering some paid leave, several interviewees described nontraditional work settings, such as being self-employed. The lack of benefits and protections in these arrangements exacerbated the financial impact of employment disruption:

"If he doesn't work, he doesn't get paid. There's no vacation, no holiday, no nothing.” (Participant \#237).

\section{Major theme \#4: Having the ability to work remotely and a supportive employer facilitated ongoing employment throughout the HSCT process}

The majority of employed wage earners in both single-earner households (71\%) and dual-earner households (68\% primary, $64 \%$ secondary) discussed their child's transplant and its impact on their work with their employer or the human resources department. Conversely, most wage earners did not discuss employment with their child's clinician (Table 4). Sole wage earners in single-earner households and primary wage earners in dual-earner households most commonly reported that their employer offered a flexible work schedule $(60 \%, 56 \%$, respectively), discussed different leave options $(52 \%, 46 \%)$, and provided additional paid time off $(43 \%, 32 \%)$ (Table 4$)$.

In interviews, participants with jobs amenable to remote work described working from the hospital while staying with their child. Though working remotely was often paired with a reduction in hours, or increased scheduling flexibility, it meant that caregivers were not forced to exhaust their FMLA while in the hospital. Several interviewees pointed to the ability to work remotely as the primary reason that they were able to maintain employment throughout the HSCT process (Table 3).

Supportive employers were described as being flexible about scheduling and time off, knowledgeable about employer-sponsored health insurance and other resources available, and empathetic to the family's situation. Some interviewees even described employers going out of their way to help the family financially, by personally raising funds or upgrading the family's health insurance plan to reduce out-of-pocket costs.

"I work for a fabulous company...They did a fundraiser, and they raised [money] for us." (Participant \#211)

In contrast, other interviewees described negative employer-employee relationships characterized by indifference or a lack of empathy or concern, which influenced their ability to maintain employment.

"I would say that the human resources at our places of employment were-I'm not sayin' they weren't concerned, but they...I don't know whether they went out of their way to help or throw other options out there... other than just get you on the Family Medical Leave Act." (Participant \#23)

\section{Discussion}

The majority of caregivers of pediatric HSCT recipients experienced employment disruption during the transplant period and extending into the years following HSCT. The loss of income and potential loss of health insurance associated with this disruption contributed to financial hardship and distress among families of pediatric HSCT recipients. In our cohort, existing employment protections were insufficient for the majority of caregivers to maintain employment throughout HSCT. However, employment accommodations, such as the ability to work remotely, gave caregivers more flexibility to maintain employment during the transplant period.

Our findings regarding the prevalence of employment disruption are largely in line with the only prior study of this topic among families of pediatric HSCT recipients [4]. A greater proportion of our sample reported substantial income loss ( $>50 \%$ of annual income), which may be, in 
part, explained by our longer follow-up period following HSCT (caregivers of patients who underwent HSCT in the prior 2 to 8 years included). Substantial employment disruption has also been previously reported among working-age caregivers of dependent pediatric and adolescent and young adult (AYA) patients with cancer [31-33]. Consistent among this and prior studies is the association between employment disruption and financial burden [4, 31, 34], which has also been documented extensively in the adult cancer and HSCT populations $[35,36]$. This suggests the need for comprehensive solutions addressing the employment challenges faced by all caregivers in their productive working years, regardless of the patient's diagnosis or treatment regimen. However, for caregivers of pediatric patients undergoing HSCT, these resources may be even more essential due to the high costs and extended treatment and recovery periods required.

Understanding employment outcomes and related challenges in caregivers of pediatric HSCT recipients is a critical first step toward developing programmatic and policy interventions to meet caregiver employment needs and mitigate the long-term financial burden. To date, the unmet supportive care, psychological, and informational needs of caregivers have been well documented as they relate to medical caregiving responsibilities [37-40]. However, less attention has been paid to the resource and informational needs stemming from employment and financial disruption.

Our findings point to the limitations of existing workplace protections and accommodations in the context of pediatric HSCT. Though FMLA provides job protection through 12 weeks of unpaid time off, caregivers only qualify if they meet criteria related to hours worked and are working at a firm with more than 50 employees [10, 41]. Additionally, 12 weeks may not be sufficient to accommodate the prolonged hospitalization and intensive outpatient follow-up care associated with HSCT. Workplace accommodations, such as flexible scheduling arrangements and remote work, were identified in our analysis as critical to balancing employment and caregiving responsibilities. The Americans with Disabilities Act (ADA), which grants reasonable accommodations to employees with disabilities, does not apply to caregivers [10, 42]. Policies are needed to ensure caregivers, particularly caregivers of pediatric patients undergoing intensive procedures such as HSCT, have equitable access to workplace accommodations and protections [43]. Such policy changes would also likely benefit caregivers of pediatric and AYA patients with cancer undergoing other intensive treatment regimens.

In the meantime, to ensure caregivers can best utilize all available employment protections, caregivers must be informed about both their employment-related needs and their rights to existing protections in order to advocate for themselves in the workplace. Equipping caregivers with this information in preparation for conversations with employers would increase the likelihood that caregivers are able to take advantage of all available accommodations and protections, despite employerrelated factors. To our knowledge, no hospital-based interventions addressing the employment and financial needs of pediatric HSCT caregivers have been developed to date. However, several evidence-based interventions, specifically web-based applications, have been developed to provide HSCT caregivers with real-time patient-specific clinical information during the transplant period $[44,45]$. Future work could expand on these applications to include information related to employment and financial planning, navigating conversations with employers, and legally mandated protections and accommodations.

These findings must be viewed in the context of several limitations. The sample for the quantitative survey was relatively small, though in line with prior studies in this population [4], and had a response rate of $36.5 \%$. This may have imposed selection bias if caregivers responding to the survey experienced more extreme financial and employment disruption. However, it is also possible that caregivers experiencing severe financial consequences post-transplant did not have the capacity to complete the survey, thus biasing results in the opposite direction. Furthermore, data collection occurred during the coronavirus disease 2019 (COVID-19) pandemic, which may have also contributed to our relatively low survey response rate. Second, results are subject to recall bias, given that we included caregivers of patients who were between 2 and 8 years post-HSCT. This was necessitated, however, by our belief in the importance of capturing the long-term impacts of HSCT on employment and finances. Lastly, this mixed methods analysis was descriptive in nature and did not examine predictors of employment disruption. Future work should consider patient, caregiver, and employment characteristics in examining the multilevel contributors to employment outcomes in this population.

In summary, employment disruption and resulting income loss were experienced by the majority of caregivers of pediatric HSCT recipients, both during the transplant period and in the years after HSCT, in two academic transplant centers in central North Carolina. Expanded employment protections and access to accommodations are needed to limit the impact of HSCT on household income, health insurance, and financial hardship. Additionally, interventions are needed to ensure caregivers are equipped with the information necessary to navigate conversations with employers and prepare for the financial and psychological reality of employment disruption.

Supplementary Information The online version contains supplementary material available at https://doi.org/10.1007/s00520-022-06883-0.

Acknowledgements We are grateful to all of the caregivers who participated in this study. We would also like to acknowledge Savannah Coble, Andrew Sharf, Richard Vinesett, Walter Armstrong, Laura Danku, Sloan Kojis, Sandi Bream, and Christina Conlin for their assistance in various phases of the data collection process. 
Author contribution All authors contributed to the study's conception and design. Funding was acquired by Lisa Spees and Kimberly Kasow. Data collection and analysis were performed by Caitlin Biddell, Lisa Spees, Sarah Drier, and Mary Killela. The first draft of the manuscript was written by Caitlin Biddell, and all authors commented on previous versions of the manuscript. All authors read and approved the final manuscript.

Funding This research was supported by the UNC Lineberger Comprehensive Cancer Center (LCCC) Developmental Funding Program supported by the University Cancer Research Fund (UCRF). CBB is supported by a NIH Cancer Care Quality Training Program grant, for which SBW is mentor and PI, UNC-CH, Grant No. T32-CA-116339. MKK is supported by a NINR Training Program grant, Interventions for Preventing \& Managing Chronic Illness, UNC-CH, Grant No. T32NR007091-25. The UNC REDCap software used for this analysis was supported by the Clinical and Translational Science Award program of the Division of Research Resources, National Institutes of Health, Grant No. UL1TR002489. NIH did not have any role in the study design; collection, management, analysis, and interpretation of the data; writing of the manuscript; or the decision to submit the report for publication.

Data availability The datasets generated during and analyzed during the current study are not publicly available due to their confidential nature.

Code availability Not applicable.

\section{Declarations}

Ethics approval The study was performed in line with the principles of the Declaration of Helsinki. Approval was granted by the Institutional Review Boards at both institutions (University of North Carolina at Chapel Hill, Duke University) (UNC-CH IRB\#19-0490).

Consent to participate Informed consent was obtained from all individual participants included in the study.

Consent for publication Not applicable.

Competing interests SBW has received funding paid to her institution from the Pfizer Foundation. JMR serves as a volunteer medical advisory board member for the nonprofit organization, The Sumaira Foundation for Neuromyelitis Optica. All other authors have no relevant financial or nonfinancial interests to disclose.

\section{References}

1. Fraint E, Holuba MJ, Wray L (2020) Pediatric hematopoietic stem cell transplant. Pediatr Rev 41(11):609-611

2. Broder MS et al (2017) The cost of hematopoietic stem-cell transplantation in the United States. Am Health Drug Benefits 10(7):366-374

3. Claxton $\mathrm{G}$ et al (2018) Increases in cost-sharing payments continue to outpace wage growth. In Peterson-KFF (ed) Health System Tracker. Kaiser Family Foundation. Available from: https:// www.healthsystemtracker.org/brief/increases-in-cost-sharingpayments-have-far-outpaced-wage-growth/. Accessed 3 Feb 2021

4. Bona $\mathrm{K}$ et al (2015) Prevalence and impact of financial hardship among New England pediatric stem cell transplantation families. Biol Blood Marrow Transplant 21(2):312-318
5. Khera $\mathrm{N}$ et al (2018) Financial hardship after hematopoietic cell transplantation: lack of impact on survival. Cancer Epidemiol Biomark Prev 27(3):345-347

6. Sands SA et al (2017) Group-based trajectory modeling of distress and well-being among caregivers of children undergoing hematopoetic stem cell transplant. J Pediatr Psychol 42(3):283-295

7. Virtue SM et al (2014) Psychological distress and psychiatric diagnoses among primary caregivers of children undergoing hematopoietic stem cell transplant: an examination of prevalence, correlates, and racial/ethnic differences. Gen Hosp Psychiatry 36(6):620-626

8. Mehnert A (2011) Employment and work-related issues in cancer survivors. Crit Rev Oncol Hematol 77(2):109-130

9. Bradley CJ (2019) Economic burden associated with cancer caregiving. Semin Oncol Nurs 35(4):333-336

10. Bradley CJ et al (2018) Cancer survivorship and employment: intersection of oral agents, changing workforce dynamics, and employers' perspectives. J Natl Cancer Inst 110(12):1292-1299

11. Hastert TA et al (2020) Employment outcomes, financial burden, anxiety, and depression among caregivers of African American cancer survivors. JCO Oncol Pract 16(3):e221-e233

12. Grunfeld E et al (2004) Family caregiver burden: results of a longitudinal study of breast cancer patients and their principal caregivers. CMAJ 170(12):1795-1801

13. Bayen E et al (2017) The multidimensional burden of informal caregivers in primary malignant brain tumor. Support Care Cancer 25(1):245-253

14. Mazanec SR et al (2011) Work productivity and health of informal caregivers of persons with advanced cancer. Res Nurs Health 34(6):483-495

15. Sautter JM et al (2014) Caregiver experience during advanced chronic illness and last year of life. J Am Geriatr Soc 62(6):1082-1090

16. Harris PA et al (2009) Research electronic data capture (REDCap)-a metadata-driven methodology and workflow process for providing translational research informatics support. J Biomed Inform 42(2):377-381

17. de Souza JA et al (2017) Measuring financial toxicity as a clinically relevant patient-reported outcome: the validation of the COmprehensive Score for financial Toxicity (COST). Cancer 123(3):476-484

18. Luker K et al (2013) A UK survey of the impact of cancer on employment. Occup Med (Lond) 63(7):494-500

19. Sowden M, Vacek P, Geller BM (2014) The impact of cancer diagnosis on employment: is there a difference between rural and urban populations? J Cancer Surviv 8(2):213-217

20. Samuel CA et al (2020) Racial differences in employment and cost-management behaviors in patients with metastatic breast cancer. Breast Cancer Res Treat 179(1):207-215

21. (2021) Dedoose version 9.0.15, web application for managing, analyzing, and presenting qualitative and mixed method research data. Sociocultural Research Consultants, LLC, Los Angeles

22. Hsieh HF, Shannon SE (2005) Three approaches to qualitative content analysis. Qual Health Res 15(9):1277-1288

23. Santacroce SJ, Kneipp SM (2019) A conceptual model of financial toxicity in pediatric oncology. J Pediatr Oncol Nurs 36(1):6-16

24. Jones SM et al (2020) A theoretical model of financial burden after cancer diagnosis. Future Oncol. 16(36):3095-3105

25. Altice CK et al (2017) Financial hardships experienced by cancer survivors: a systematic review. J Natl Cancer Instit 109(2):djw205. https://doi.org/10.1093/jnci/djw205

26. Chebli $\mathrm{P}$ et al (2020) Multilevel determinants of financial toxicity in breast cancer care: perspectives of healthcare professionals and Latina survivors. Support Care Cancer 28(7):3179-3188

27. Dean LT et al (2019) "It still affects our economic situation": long-term economic burden of breast cancer and lymphedema. Support Care Cancer 27(5):1697-1708 
28. Taplin SH et al (2012) Introduction: understanding and influencing multilevel factors across the cancer care continuum. J Natl Cancer Instit. Monographs 2012(44):2-10

29. Tong A, Sainsbury P, Craig J (2007) Consolidated criteria for reporting qualitative research (COREQ): a 32-item checklist for interviews and focus groups. Int J Qual Health Care 19(6):349-357

30. Creswell JW (2015) A concise introduction to mixed methods research. Sage Publications, Thousand Oaks, pp 35

31. Warner EL et al (2015) Financial burden of pediatric cancer for patients and their families. J Oncol Pract 11(1):12-18

32. Bona $\mathrm{K}$ et al (2014) Economic impact of advanced pediatric cancer on families. J Pain Symptom Manage 47(3):594-603

33. Hjelmstedt $S$ et al (2021) Facilitators and barriers to return to work and meet financial needs in parents of children with cancer. Pediatr Blood Cancer 68(10):e29245. https://doi.org/10.1002/pbc. 29245

34. Aung L et al (2012) The hidden impact of childhood cancer on the family: a multi-institutional study from Singapore. Ann Acad Med Singapore 41(4):170-175

35. Mols F et al (2020) Financial toxicity and employment status in cancer survivors. A systematic literature review. Support Care Cancer 28(12):5693-5708. https://doi.org/10.1007/ s00520-020-05719-z

36. Albelda R et al (2019) Relationship between paid leave, financial burden, and patient-reported outcomes among employed patients who have undergone bone marrow transplantation. Qual Life Res 28(7):1835-1847

37. Devine KA et al (2016) Barriers to psychological care among primary caregivers of children undergoing hematopoietic stem cell transplantation. Support Care Cancer 24(5):2235-2242
38. Kaziunas E et al (2016) Identifying unmet informational needs in the inpatient setting to increase patient and caregiver engagement in the context of pediatric hematopoietic stem cell transplantation. J Am Med Inform Assoc: JAMIA 23(1):94-104

39. Mangurian $\mathrm{C}$ et al (2018) The need to support caregivers during pediatric bone marrow transplantation (BMT): a case report. Palliat Support Care 16(3):367-370

40. Yoo J et al (2019) Supporting caregivers during hematopoietic cell transplantation for children with primary immunodeficiency disorders. J Allergy Clin Immunol 143(6):2271-2278

41. (2012) Fact Sheet \#28A: Employee Protections under the Family and Medical Leave Act. https://www.dol.gov/agencies/whd/factsheets/28a-fmla-employee-protections. Accessed 3 Feb 2021

42. (2013) Cancer in the workplace and the ADA. [cited 20213/2/21]; Available from: https://www.eeoc.gov/laws/guidance/cancerworkplace-and-ada

43. Williams JC et al (2012) Protecting family caregivers from employment discrimination. AARP Public Policy Institute, Insight on the Issues, p 68

44. Runaas L et al (2017) BMT Roadmap: a user-centered design health information technology tool to promote patient-centered care in pediatric hematopoietic cell transplantation. Biol Blood Marrow Transpl 23(5):813-819

45. Mayer DK et al (2010) Development of a health-related website for parents of children receiving hematopoietic stem cell transplant: HSCT-CHESS. J Cancer Survivorship 4(1):67-73

Publisher's note Springer Nature remains neutral with regard to jurisdictional claims in published maps and institutional affiliations. 